EPJ Web of Conferences 45, 01102 (2013)

DOI: $10.1051 /$ epjconf/20134501102

(C) Owned by the authors, published by EDP Sciences, 2013

\title{
The influence of air duct geometry on air jet direction in aircraft cabin ventilated by mixing ventilation.
}

\author{
J. Fišer ${ }^{1, a}$ and M. Jícha ${ }^{1}$ \\ ${ }^{1}$ Faculty of mechanical Engineering, Brno University of Technology, Technicka 2, 61669 Brno, Czech Republic
}

\begin{abstract}
The paper deals with instigation of influence of air duct geometry on air jet direction in aircraft cabin ventilated by mixing ventilation. CFD approach was used for investigation and model geometry was based on small aircraft cabin mock-up geometry. Model was also equipped by nine seats and five manikins that represent passengers. The air jet direction was observed for selected ambient environment parameters and several types of air duct geometry and influence of main air duct geometry on jets direction is discussed. The model was created in StarCCM+ ver. 6.04.014 software and polyhedral mesh was used.
\end{abstract}

\section{Introduction}

The main factors which create an internal environment in cabins ventilated by mixing ventilation are parameters and the locations of air distribution outlets [1]. From principle of mixing ventilation the essential parameters for the quality of the internal environment are not only amount of distributed fresh air, but also the direction of primary jets which creates flow pattern $[2,3,4]$. One of the fundamental issues in the CFD modelling of the cabin environment ventilated by mixing ventilation is to finding appropriate methods for representation of parameters and geometry of air distribution system. Frequently used method is modelling by using an equivalent area of distribution outlet with combination of air velocity of supplied air (see figure 1).

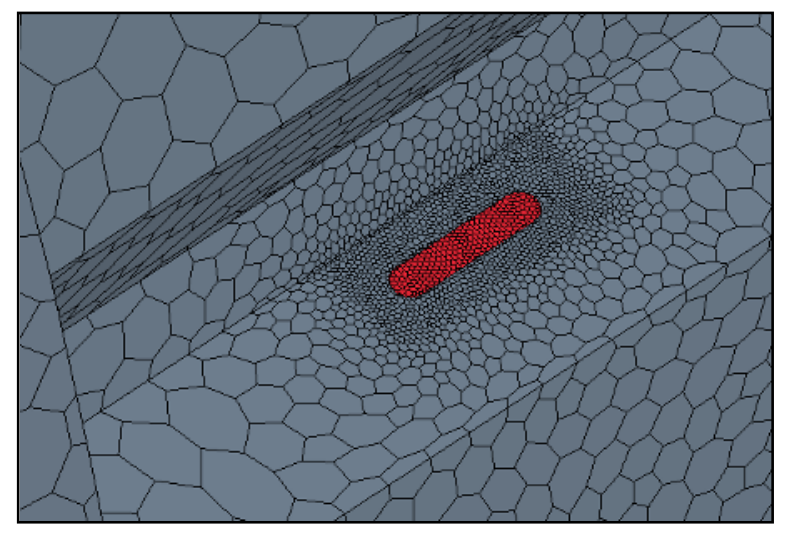

Fig. 1. Equivalent area method of distribution outlet (red area is inlet boundary condition with prescribed velocity).

This method is a fundamental and is implemented in all available commercial CFD codes. The method is based on replacing the complex geometry of the distribution outlet by the simple surface geometry which represents same area and respects main shapes of modelled outlet. Prescribed inlet velocity perpendicular to the surface is then calculated as the volumetric flow rate divided by the total open area of outlet. Real free/open area is in many cases difficult to determine and the method does not take into account the possible influence of distribution air duct. This procedure can lead to inaccuracies in the calculation of the jet entrainment and penetration length of the jet [1]. Chen and Moser [5] also showed that the method is not suitable for non-isothermal jets. Therefore, in the nineties of the twentieth century a number of procedures for better description of the flow field generated by distribution outlets were developed. For example: momentum model [5], box model [1], prescribe velocity method [1] etc. The main disadvantage of all these methods is the fact that they need special types of boundary condition, which are not available in most commercial software or need knowledge of the specific characteristics of flow fields in front of outlet which can be usually obtained only by measurement.

Due to the rapidly growing performance of computers in last years it is possible to use full geometry representation method. This method includes outlet and air duct geometry into the model geometry (see figure 2). and does not require any special types of boundary conditions or flow field measurements in front of real outlet. On the other hand, the method increases the number of cells and increases computational cost, but this increase is according to $[1,6]$ in a range of 5 or $10 \%$.

The author of the paper used Full representation method of distribution system for simulation of cabin environment in mock-up of small transport aircraft. The simulated scenarios lead to simulation of non-isothermal

${ }^{\mathrm{a}}$ fiser@fme.vutbr.cz 
jets in the cabin. Another important part of investigation was influence of air duct on parameters of flow field and primary jets parameters.

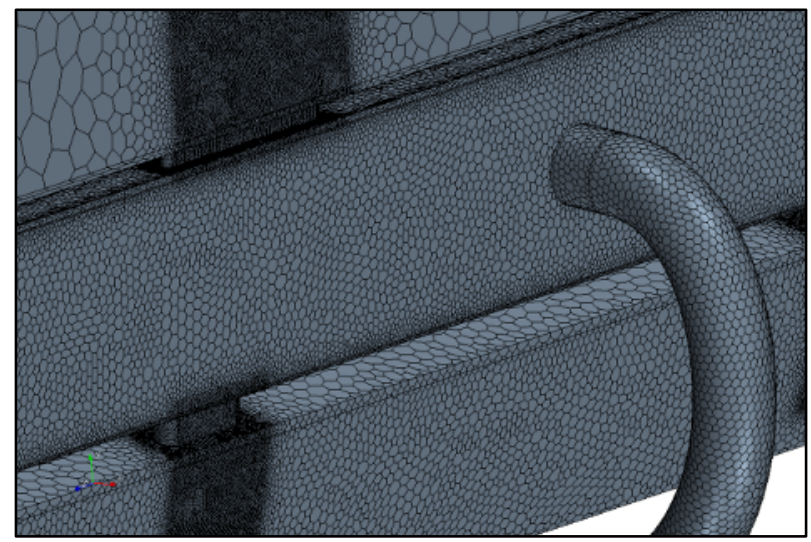

Fig. 2. Full representation method includes geometry of outlets and air duct into the CFD model geometry.

\section{Model geometry}

The mock-up of small aircraft cabin is located in heavy laboratories of Department of Thermodynamics and Environmental Engineering. It consists of a cockpit at the fore, cabin for passengers in the middle and cargo compartment at the rear (see figure 4). All parts of the cabin create a single space without bulkheads. The mock-up of the cabin is $7.26 \mathrm{~m}$ long, $1.42 \mathrm{~m}$ wide and $1.38 \mathrm{~m}$ high. The total volume of the cabin is $14.5 \mathrm{~m}^{3}$. The view to the cabin mock-up interior is in figure 3 .

The layout of the cabin geometry model is in the figure 4 . In the cabin there are nine seats in five rows; five seats are located on the right side and four are located on the left side. Seats in row 1,3 and 5 are occupied by manikins. Dimensions of manikin represents average surface of adult men with height equal to $1,8 \mathrm{~m}$.

The ventilation system of the cabin is based on mixing ventilation. The air is supplied to the distribution outlets by distribution air duct situated on the left and right side of the cabin.

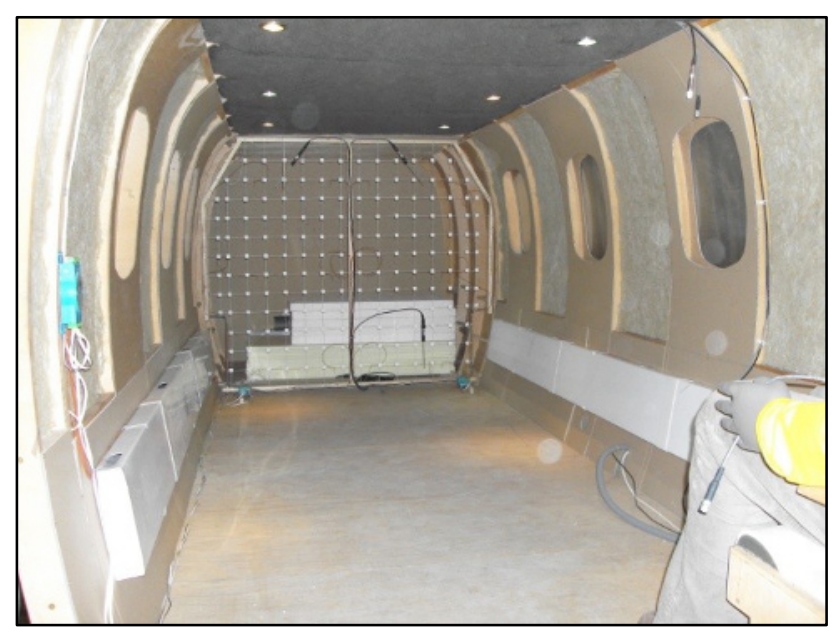

Fig. 3. Real interior of small aircraft cabin mock-up (main door to cockpit view).
Two types of distribution air duct geometry were investigated in presented study. The first was typical distribution system for mixing ventilation with circular crosscut of air duct with diameter $100 \mathrm{~mm}$. The air duct feeds nine distribution outlets, one for each seat (see figure 5).

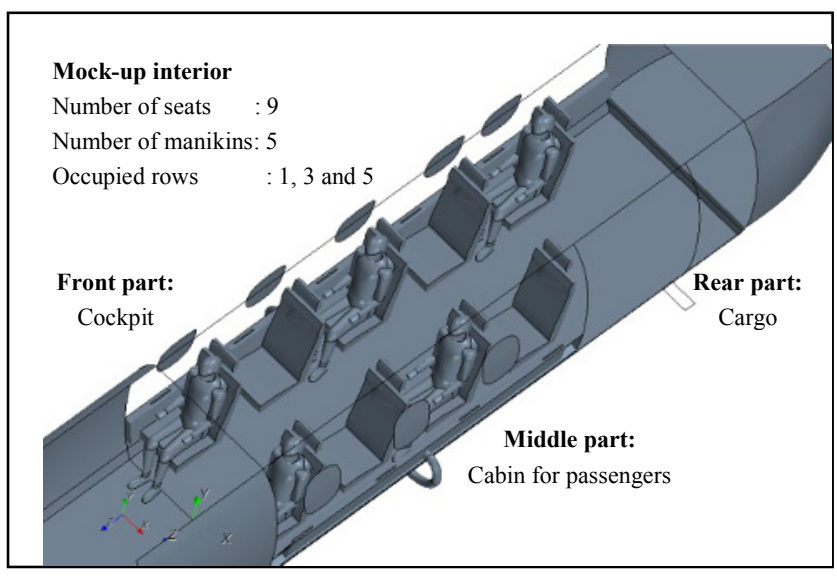

Fig. 4. Geometry of the mock-up, seats and manikins for CFD model

The second one was distribution system for mixing ventilation with modified geometry of air distribution ducts. The crosscut of the duct was rectangular with dimensions $50 \times 215 \mathrm{~mm}$. The air duct feeds eighteen distribution outlets, two for each seat (see figure 6). Detail description of studied cases and boundary conditions is in the chapter 3.

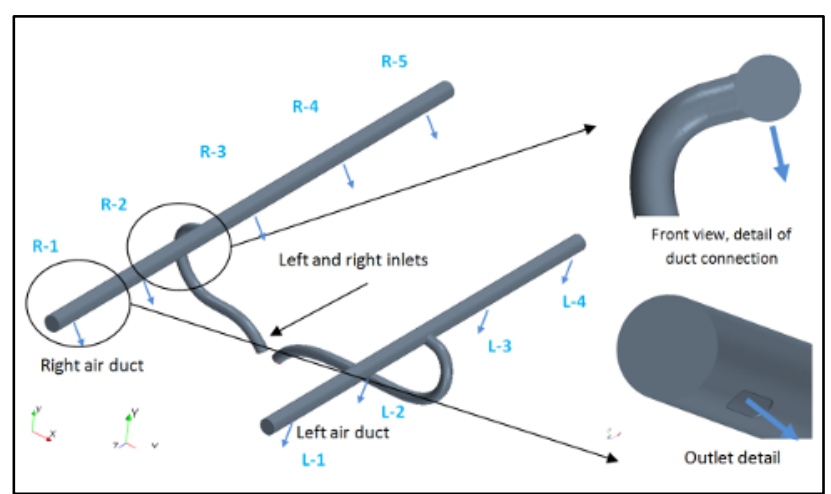

Fig. 5. Geometry of typical distribution air duct with circular crosscut and nine outlets (marked as R1-R5 and L1-L5)

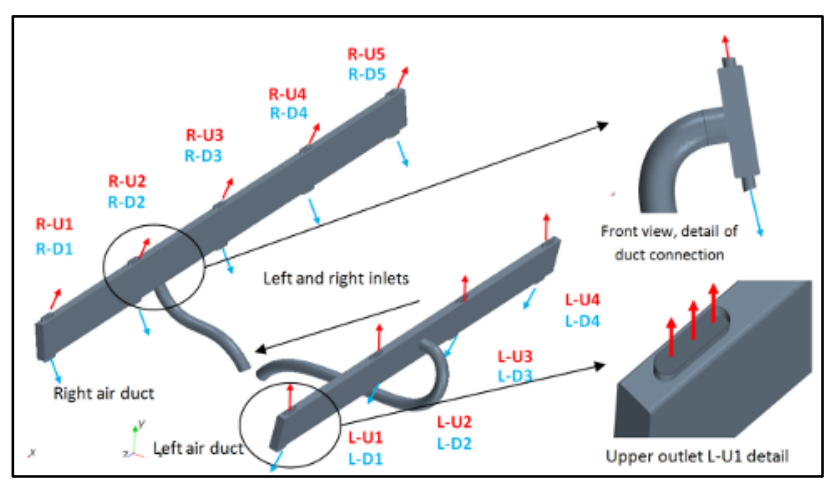

Fig. 6. Geometry of modified distribution air duct with rectangular crosscut and eighteen outlets (marked as R-U/D1 to R-U/D5 and L-U/D1 to L-U/D4) 


\subsection{Computational mesh}

The computational mesh for the CFD simulations was created in the software StarCCM+ 6.04.014 and polyhedral cell approach was used for generation of mesh. The mesh in cabin space consists mostly of polyhedral cells with prismatic layer generated near the walls and manikins. The total number of cells in model was approximately 7 millions. The target size of the interior cells was set to $0.05 \mathrm{~m}$ with minimum cell size $0.025 \mathrm{~m}$. A much finer surface mesh and volume mesh is required to capture small geometric features like outlets as their correct captured shape and further refinement is necessary for prediction of correct discharge flow from them (see figure 2.) Consequently the amount of volume cells spent for the outlets refinement volumes can match or even exceed the cell count of the main cabin. The view to polyhedral mesh crosscut on the right side of the model is depicted in figure 7 .

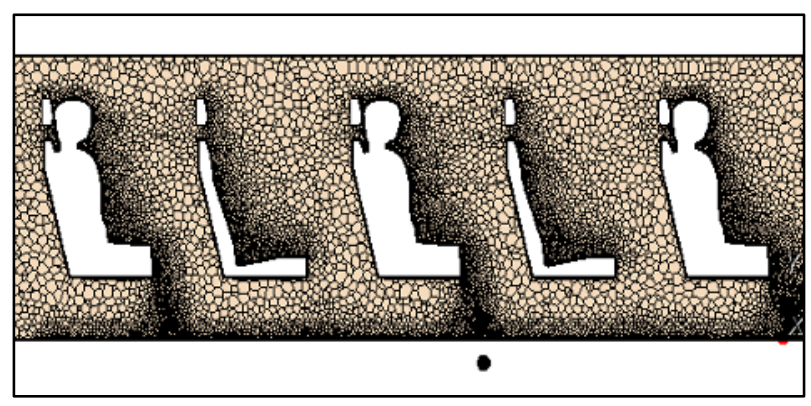

Fig. 7. Right side crosscut of the computational mesh of cabin for passengers

The model for near wall treatment based on value of $\mathrm{y}^{+}$was used in simulations, therefore fine near wall resolution of mesh was necessary near cabin walls and virtual manikins and course mesh was used in air ducts. The correct representation of the heat flux from surfaces plays significant role in the prediction of the temperature distribution in the cabin. Therefore the prismatic layer was defined at the walls. The thickness of this layer was 1 $\mathrm{cm}$. The detail of the computational mesh near the virtual manikin is displayed in the figure 8 .

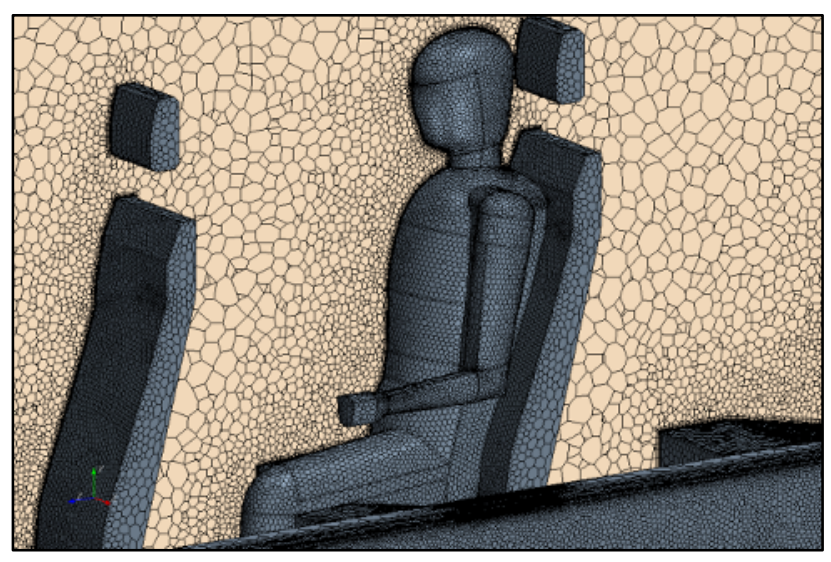

Fig. 8. Detail of mesh near the virtual manikin and seats

\section{Studied cases and boundary conditions}

The studied cases were divided into three main groups based on type of geometry of distribution air duct and type of connection of feed air hose. The first group of cases A contains cases with typical mixing distribution air duct where in case A01 the feed hose is connected between outlets L2/L3 and R2/R3 (see figure 5) and in case A02 the feed hose is connected between outlets L3/L4 and R3/R4. The second group of cases B contains cases with modified mixing distribution air duct where in case B01 the feed hose is connected between outlets L-D2/L-D3 and R-D2/R-D3 (see figure 6) and in case B02 the feed hose is connected between outlets L-D3/L-D4 and R-D3/R-D4. The last group of cases C contains cases with modified mixing distribution air duct where in case $\mathrm{C} 01$ the air is fed to air distribution duct from inlet in front of the duct and in the case $\mathrm{C} 02$ the air is fed from inlet in the rear of the distribution duct (see figure 9).

Table 1. Groups and main characteristics of studied cases

\begin{tabular}{|c|c|c|c|}
\hline & $\begin{array}{c}\text { Type of } \\
\text { distribution }\end{array}$ & Case & Type of inlet \\
\hline \multirow{2}{*}{ Group A } & \multirow{2}{*}{ Mixing } & A01 & Hose - central \\
\hline & & $\mathrm{A} 02$ & Hose - rear \\
\hline \multirow{2}{*}{ Group B } & \multirow{2}{*}{ Mixing modified } & B01 & Hose - central \\
\hline & & B02 & Hose - rear \\
\hline \multirow{2}{*}{ Group C } & \multirow{2}{*}{ Mixing modified } & $\mathrm{C} 01$ & Direct front \\
\hline & & $\mathrm{C} 02$ & Direct rear \\
\hline
\end{tabular}

\subsection{Cabin boundary conditions}

The temperature of supply air was based on volumetric flow rate and demanded temperature inside the cabin. For all cases the volumetric flow rate was set to same value of $66 \mathrm{l} / \mathrm{s}$. This value is based on performance of ventilation system of real cabin mock-up. The speed of air on inlet boundary condition was for cases in group A and B: inlet to the left hose $8.18 \mathrm{~m} / \mathrm{s}$ (volumetric flow rate $29.3 \mathrm{l} / \mathrm{s}$ ), inlet to the right hose $10.41 \mathrm{~m} / \mathrm{s}$ (volumetric flow rate $36.7 \mathrm{l} / \mathrm{s}$ ).

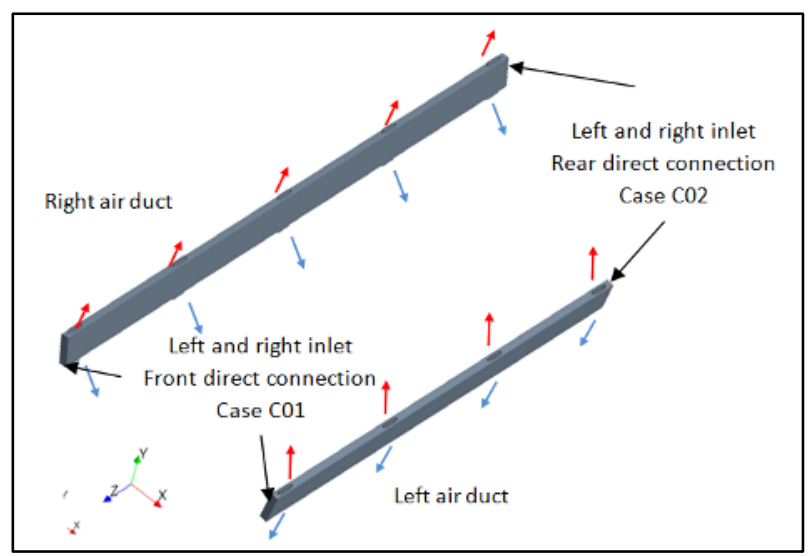

Fig. 9. Location of inlets for cases $\mathrm{C} 01$ - direct front and $\mathrm{C} 02$ direct rear 
For cases in group C: inlet to the left air duct $2.74 \mathrm{~m} / \mathrm{s}$ (volumetric flow rate $29.3 \mathrm{l} / \mathrm{s}$ ), inlet to the right air duct $3.49 \mathrm{~m} / \mathrm{s}$ (volumetric flow rate $36.7 \mathrm{l} / \mathrm{s}$ ). The ambient temperature was set to $15{ }^{\circ} \mathrm{C}$ which results in supply air temperature of $26{ }^{\circ} \mathrm{C}$ and cabin temperature of $24^{\circ} \mathrm{C}$. More detail description of simulation can be found in [7].

\subsection{Manikin boundary conditions}

The waste heat generated by passengers in real cabin creates buoyancy plume around each sitting person. These plumes interacts with main flow pattern generated by ventilation system [8]. Therefore, the virtual manikins representing passengers were located at seats in rows 1,3 and 5 which leads to five manikins in cabin model. For setup of boundary condition on manikins the procedure from work of H.O. Nilsson [9] was adopted and the manikins geometry and boundary conditions were defined to be ready for use of equivalent temperature concept. On unclothed parts such as hands and face, the surface temperature $34{ }^{\circ} \mathrm{C}$ was prescribed. On parts with clothing the skin temperature $34{ }^{\circ} \mathrm{C}$ together with thermal resistance of clothing were prescribed. The thermal resistances of clothing were based on summer clothing [9].

\section{CFD methodology and Results}

Following assumptions were made for simulations setup. The buoyancy and radiation effect within the cabin were taken into account. Surface to Surface radiation model was used. The flow is assumed to be turbulent and the $\mathrm{k}-\omega \mathrm{SST}$ turbulence model was applied. The properties of air in the cabin were governed by equation of state for ideal gas where the reference pressure was set to $97910 \mathrm{~Pa}$. Due the large amount of the results only the selected important results are presented here. All presented figures from CFD simulation are plotted as isosurfases, view from the left side of the model. Directions of primary air jets are represented by the inclination angle which is measured between plane $X-Y$ and projection of jet axis into plane $\mathrm{Y}-\mathrm{Z}$ (positive sign $=$ direction with $Z$ axis direction, negative sign $=$ direction of the jet in negative $Z$ axis direction).

\subsection{Mixing ventilation - central and rear connection of feed hose(Cases A01 and A02)}

The results for group A are depicted in figures 10 and 11 . These figures present isosurface of velocity with magnitude of $0.8 \mathrm{~m} / \mathrm{s}$. The figure 10 shows direction of primary jets from outlets for case A01 where the air feed hose is connected in central position and the figure 11 shows results for case A02 where the air feed hose is connected between outlets L3/L4 and R3/R4. The figures illustrate quite well the main impact of air distribution hose location. The jets generated by outlets which are nearest to the feed hose have highest inclination angle. When the outlet is more far from the feed hose then the inclination angle is smaller and the smallest angle was observed on terminal outlets (L1/R1, L4 and R5).
The values of inclination angles are shown in Table 2 . As can be seen the inclination angle for terminal outlets in front part of the cabin for passengers is almost same for both cases (of example case A01 L1/R1 $=9^{\circ}$, for A02 $\mathrm{L} 1 / \mathrm{R} 1=9^{\circ}$ ). Different situation is for jets generated by terminal outlet L4 and R5. In case A01, when the hose is in the central position, the angles of jets L4, R5 is almost same as from front terminal outlets. But for case A02 the situation is different. The flow field inside air distribution duct is directly influenced by rear position of the hose and angles are equal to values $\mathrm{L} 4=-12^{\circ}$ and $\mathrm{R} 5=0^{\circ}$. Also jets from other outlets are influenced by hose position. For example inclination angle of jet generated by outlet L 3 changed from $-35^{\circ}$ for case A01 to opposite direction of $42^{\circ}$ for case $\mathrm{A} 02$.

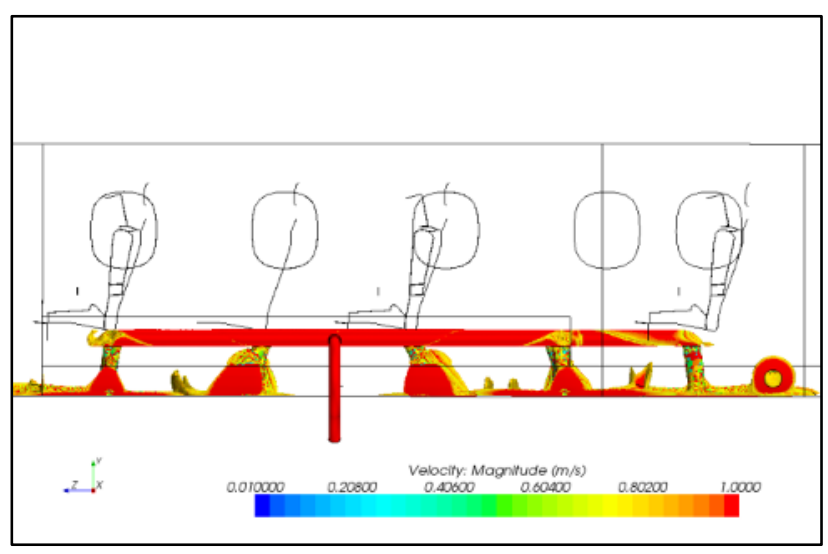

Fig. 10. Direction of jets from distribution outlets - central connection of the air hose - isosurface $0.8 \mathrm{~m} / \mathrm{s}$ - left view - case A01

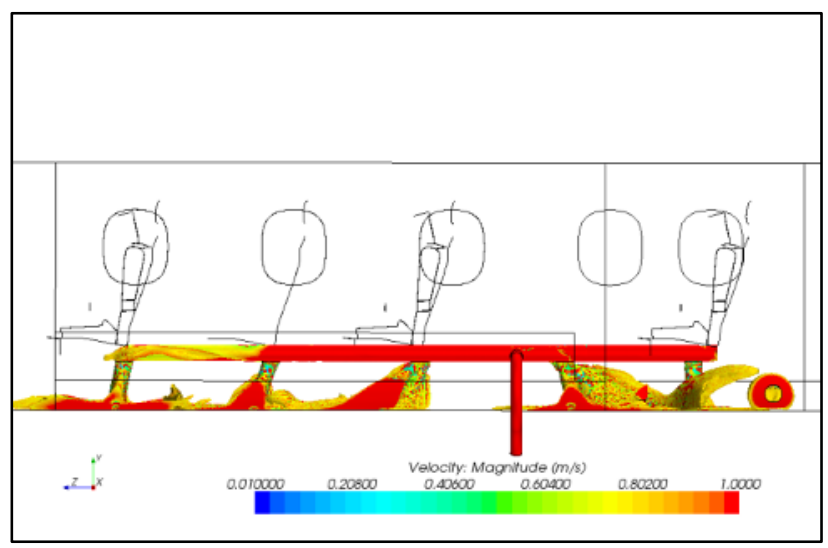

Fig. 11. Direction of jets from distribution outlets - rear connection of the air hose - isosurface $0.8 \mathrm{~m} / \mathrm{s}$ - left view - case A02

Table 2. Jets inclination angle for group A

\begin{tabular}{|c|c|c|c|c|c|}
\hline & L1/R1 & L2/R2 & L3/R3 & L4/R4 & R5 \\
\hline $\begin{array}{c}\text { Case } \\
\text { A01 }\end{array}$ & $9 / 9$ & $34 / 34$ & $-35 /-35$ & $-8 /-13$ & -9 \\
\hline $\begin{array}{c}\text { Case } \\
\text { A02 }\end{array}$ & $9 / 9$ & $20 / 20$ & $42 / 42$ & $-12 /-51$ & 0 \\
\hline
\end{tabular}




\subsection{Mixing modified ventilation - central and rear connection of feed hose (Cases B01 and B02)}

Main results of CFD simulation for group of cases B are depicted in figures 12 and 13. This figures presents isosurface of velocity with magnitude of $0.5 \mathrm{~m} / \mathrm{s}$ coloured by velocity magnitude. The first figure 12 shows direction of main jets from inlets for case B01 where the air distribution hose is connected in central position and the figure 13 shows results for case B02 where the air distribution hose is connected between outlets L-U3/LU4 and R-U3/R-U4. The figures illustrate quite well the main impact of location of air distribution hose. The jets generated by outlets which are nearest to distribution hose have highest inclination angle (positive or negative). When the outlet is more far from feeding hose then the inclination angle is smaller and the smallest angle was observed on terminal outlets (L-U1/R-U1, L-U4 and RU5).

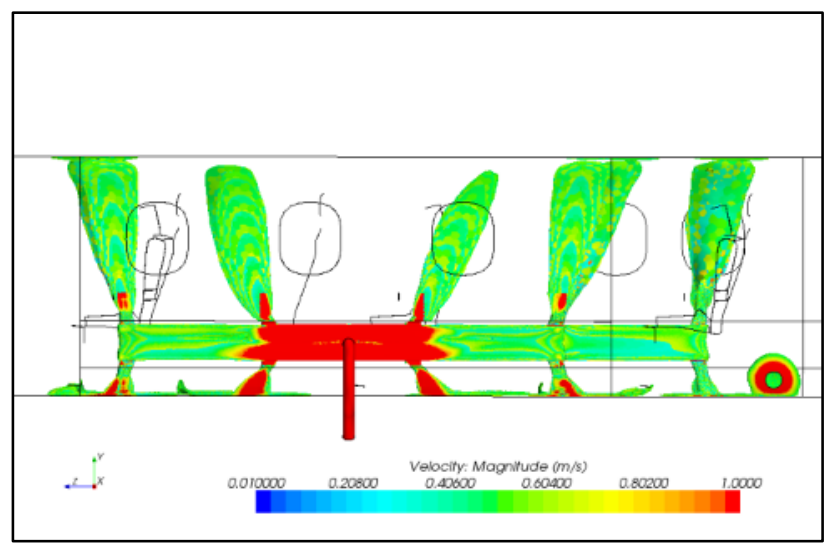

Fig. 12. Direction of jets from distribution outlets - central connection of the air hose - isosurface $0.5 \mathrm{~m} / \mathrm{s}$ - left view - case B01

The values of inclination angles are shown in Table 3 (for upper distribution outlets only). As can be seen for both cases the inclination angle for terminal outlets in front part of the cabin for passengers are almost same for both cases (of example case B01, L-U1/R-U1 $=10^{\circ}$ and for B02, L-U1/R-U1 $=13^{\circ}$ ). Different situation is for jets generated by terminal outlet L-U4 and R-U5. In case B01 when the hose is in the central position the angles of jets L-U4, R-U5 is almost same as from front terminal outlets. But for case B02 the situation is different, the flow field inside air distribution duct is directly influenced by rear position of hose and angles are equal to values $\mathrm{L} 4=-36^{\circ}$ and $\mathrm{R} 5=-13^{\circ}$. Also jets from other outlets are influenced by hose position. For example inclination angle of jet generated by outlet L-U3 changed from $-27^{\circ}$ for case $\mathrm{B} 01$ to opposite direction of $21^{\circ}$ for case $\mathrm{B} 02$.

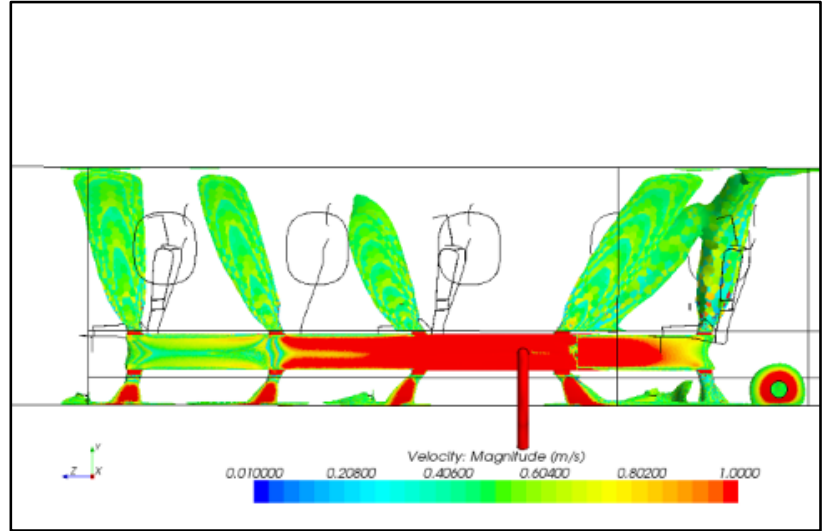

Fig. 13. Direction of jets from distribution outlets - rear connection of the air hose - isosurface $0.5 \mathrm{~m} / \mathrm{s}-$ left view - case B02

Table 3. Jets inclination angle for group B - data for upper distribution outlets only

\begin{tabular}{|c|c|c|c|c|c|}
\hline & L1/R1 & L2/R2 & L3/R3 & L4/R4 & R5 \\
\hline $\begin{array}{c}\text { Case } \\
\text { B01 }\end{array}$ & $10 / 10$ & $14 / 14$ & $-27 /-27$ & $-10 /-25$ & -10 \\
\hline $\begin{array}{c}\text { Case } \\
\text { B02 }\end{array}$ & $13 / 13$ & $21 / 21$ & $21 / 21$ & $-36 /-51$ & -13 \\
\hline
\end{tabular}

\subsection{Mixing modified ventilation - direct connection (Cases C01 and C02)}

Main results of CFD simulation for group of cases $\mathrm{C}$ are depicted in figures 14 and 15. This figures present isosurface of velocity with magnitude of $0.5 \mathrm{~m} / \mathrm{s}$. The figure 14 shows direction of main jets from inlets for case C01 where the air inlet is prescribed at the front part of the air distribution ducts and the figure 13 shows results for case $\mathrm{C} 02$ where the air inlet is prescribed at the rear part of the air distribution ducts. The direction of jets generated by outlets is different for front (case C01) and rear (case C02) inlet. When the air is distributed from inlet in front part of the air ducts the inclination angles are negative and the values of inclination of jets from outlets in same row is different (for example L-U3 $=-21^{\circ}$ and R-U3 $=-28^{\circ}$ ).

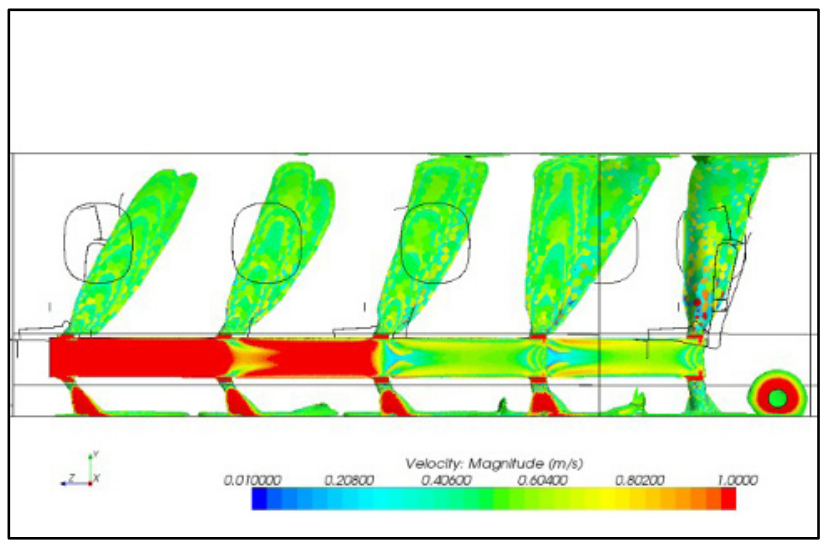

Fig. 14. Direction of jets from distribution outlets - front direct inlet - isosurface $0.5 \mathrm{~m} / \mathrm{s}$ - left view - case C01 
On the other hand, when the air is distributed from inlet in rear part of air ducts the inclination angles are positive and the values of inclination of jets from outlets in same row is equivalent (for example L-U3 $=24^{\circ}$ and

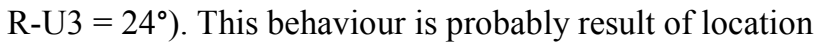
of cabin air exhaust outlet which is situated in the right bottom part of all figures with results. In case $\mathrm{C} 01$ the jets for terminal inlets are influenced by close position of cabin air exhaust outlet, but in case $\mathrm{C} 02$ when direction of all jets is toward front part of the cabin, the influence of cabin air exhaust outlet is negligible. The value of inclination angles are shown in Table 4 (for upper distribution outlets only). As can be seen the inclination angle for terminal outlets is almost same for both cases (of example case C01, L-U4/R-U5 $=-11^{\circ}$ and for C02, $\left.\mathrm{L}-\mathrm{U} 1 / \mathrm{R}-\mathrm{U} 1=9^{\circ}\right)$.

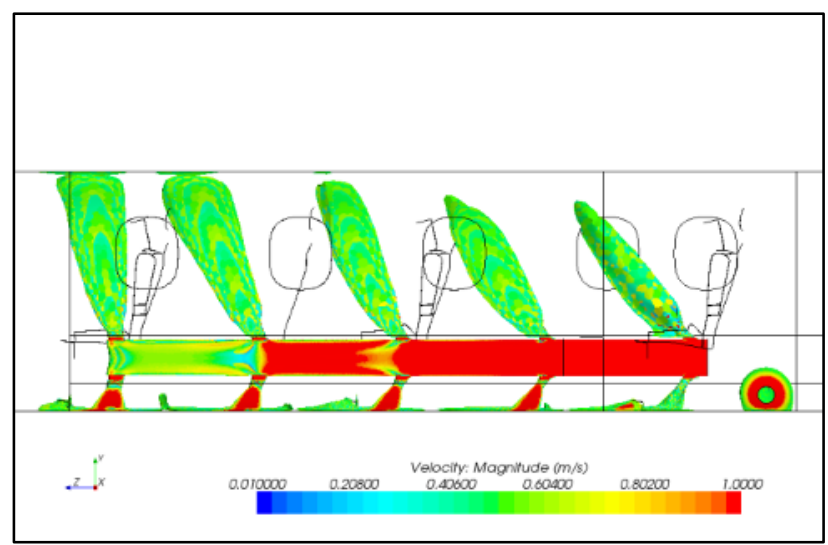

Fig. 15. Direction of jets from distribution outlets - rear direct inlet - isosurface $0.5 \mathrm{~m} / \mathrm{s}$ - left view - case C02

Table 4. Jets inclination angle for group C - data for upper distribution outlets only

\begin{tabular}{|c|c|c|c|c|c|}
\hline & L1/R1 & L2/R2 & L3/R3 & L4/R4 & R5 \\
\hline $\begin{array}{c}\text { Case } \\
\text { C01 }\end{array}$ & $-32 /-39$ & $-24 /-34$ & $-21 /-28$ & $-11 /-28$ & -11 \\
\hline $\begin{array}{c}\text { Case } \\
\text { C02 }\end{array}$ & $9 / 9$ & $23 / 23$ & $24 / 24$ & $34 / 34$ & 41 \\
\hline
\end{tabular}

\section{Conclusions}

The instigation of influence of air duct geometry on air jet direction generated by air distribution outlet in aircraft cabin ventilated by mixing ventilation was done. CFD approach was used for investigation and model geometry was based on small aircraft cabin mock-up geometry.

From obtained results can be concluded:

- The geometry of main distribution duct with sufficient level of detail should be included in the geometry of CFD model, because direction of air jets generated by air distribution outlets is strongly influenced by air duct geometry.

- The jet direction is most influenced by close connection of main feed hose or by close location of main cabin air exhaust outlet.
- The proper prediction of air jet direction is important for prediction of quality of ventilation, thermal comfort and cabin environment parameters in cabin of small aircraft. Therefore the geometry of air distribution duct should be included in CFD simulations where main purpose of simulation are focused to the aims mentioned above.

\section{Acknowledgement}

Author gratefully acknowledges the support of Faculty of mechanical engineering project FSI-S-11-6 and project CZ.1.07/2.3.00/30.0005.

\section{References}

1. F. Kuznik, J. Brau, The international journal of ventilation - volume 4, number 2 (2005)

2. J. Bosbach, J. Pennecot, C. Wagner, M. Raffel, T. Lerche, S. Repp, Energy, 31, 694-705 (2006)

3. J.C. Kok, J. Van Muijden, EUROMECH Colloquium 471 (Göttingen, Germany, 2005)

4. T. Zhang, P. Li, S. Wang, Building and Environment 47, 89-99 (2012)

5. Q. Chen, A. Moser, 12th AIVC Conference (Ottawa, Canada, 1991)

6. P. Emvin, L. Davidson, Roomvent 1996, Vol. 1, 219-226 (Yokohama, Japan, 1996)

7. J. Fišer, Optimalizace mikroklimatu v kabinách malých dopravnich letadel, $\mathrm{PhD}$ thesis, (Brno, 2011)

8. T. Zhang, Q. Chen, Building and Environment, 42, 1675-1684 (2007)

9. H.O. Nilsson, Comfort Climate Evaluation with Thermal Manikin Methods and Computer Simulation Models, PhD thesis (University of Gävle, 2004) 